\title{
Проблема этнической толерантности у студентов современных вузов
}

В данной статье поднята одна из актуальных проблем на сегодняшней день для системы высшего образования - проблема этнической толерантности в прочессе обучения. Приведено исследование динамики этнической толерантности у русских студентов в ходе совместного обучения с представителями различных этнических групп. В исследовании приняли участие 120 человек-студенты 2-4 курсов. Показано, что для студентов старших курсов характерна более высокая этническая толерантность по отношению к представителям других культур.

Ключевые слова: этническая толерантность, студенческая среда, тип толерантности.

Российская система образования на современном этапе развития указывает на одну из ключевых на сегодняшний день проблем - проблему межэтнических отношений в образовательном процессе. Поэтому одной из основных задач образовательного процесса в современных вузах является формирование толерантности и укрепление межнационального и межкультурного взаимодействия. Внедрение в систему образования новых стандартов (ФГОС ВПО) ведет к глобальным изменениям в системы высшего профессионального образования. Ориентируясь на современные требования рынка труда, можно увидеть, что изменились и требования работодателей к качеству подготовке специалистов, появляется много новых профессий и специализаций, что приводит к миграции населения к крупным образовательным центрам [7, 10]. Сегодня вуз представляет собой не только образовательный, научно-исследовательский центр, но и центр поликультурного взаимодействия. Поэтому понятие «этническая толерантность» стремительно вошло в образовательный процесс, особенно в последнее время. Этническая толерантность и ее структурные компоненты стали предметом современных психологических, социальных, политических исследований. В нашем обществе, для которого характерно наличие различных форм проявления нетерпимости, ксенофобии, экстремизма и терроризма, проблема этнической толерантности стала одной из актуальных.

Под этнической толерантностью принято понимать способность человека проявлять терпение к образу жизни представителей других этнических общностей, их поведению, национальным традициям, идеям, верованиям и т. д. Также этническая толерантность понимается как личностное образование, входящее в структуру социальных установок.

К структуре этнической толерантности можно отнести следующие компоненты: когнитивный (знания об особенностях культурной жизни других этнических групп, понимание феномена толерантности и т. д.), эмоциональный (отношение 
к другим этническим группам), поведенческий (проявление толерантного/интолерантного поведения, стремление к общению и т. д. с представителями других этнических групп).

Этническая толерантность формируется в сфере сознания и тесно связана с таким социально-психологическим фактором, как этническая идентичность, которая формируется в процессе социализации, в процессе становления личной идентичности, проходя личностно-психологический уровень (осознание человеком, кто есть Я), а затем социально-психологический, когда формируются представления о себе как о члене той или и ной группы, т. е. идет формирование этнической идентичности.

Внешне этническая толерантность отражается в выдержке, самообладании, способности индивида длительно выносить непривычные воздействия чужой культуры без снижения его адаптивных возможностей. Также проявляется в критических ситуациях межличностного и внутриличностного выбора, сопровождаясь психологической напряженностью. Степень ее выраженности зависит от наличия опыта общения человека с представителями других этнических общностей $[1,2$, $3,4]$. Формирование этнической толерантности тесно связано с экономическими, политическими и социокультурными условиями среды, в которой развивается студент [6, 9].

Особенно оказывают влияние на формирование этнической толерантности у студентов СМИ. Рассматривая этническую толерантность в связи с деятельностью СМИ, которые занимаются освещением проблем межнациональных отношений, следует отметить, что их деятельность должна быть направлена на борьбу против этнического и расового рассогласования, против негативного восприятия представителей других этнических групп, против расовой дискриминации представителей других национальностей и т. д. К сожалению, большинство средств массовой информации не несут в себе принципов гуманизма и толерантности.

Следует помнить, что студенческий возраст - это период не только становления будущего профессионала, но и период развития этнического самосознания $[2,8,11,12,14]$. Неопределенность социального положения побуждает молодых людей к поиску самоопределения, а неустойчивость ценностной сферы делает их более восприимчивыми к различного рода влияниям и, как следствие, происходит развитие интолерантных установок, гиперидентичности в сфере этнического самосознания. Многолетние исследования трансформации российского общества показывают широкое распространение интолерантного отношения к представителям других этнических групп в молодежной среде [5].

Студенчество представляет собой активную часть общества, поэтому проблема этнической толерантности в вузовской среде обостряется и требует к себе более активного внимания.

Целью нашего исследования стало изучение особенностей динамики этнической толерантности и типа доминирующей этнической толерантности у студентов старших курсов. 
Объектом исследования стали русские студенты 2-4 курсов факультета психологии в количестве 120 человек.

В ходе исследования нами были использованы следующие методики: экспрессопросник «Индекс толерантности» (Г.У. Солдатова с соавт.) для диагностики общего уровня толерантности личности; «Типы этнической идентичности» (Г. У. Солдатова, С. В. Рыжова) позволяет диагностировать этническое самосознание и его трансформации в условиях межэтнической напряженности; методика «Диагностики общей коммуникативной толерантности» (В. В. Бойко) позволяет диагностировать толерантные и интолерантные установки личности, проявляющиеся в процессе общения по 9 шкалам. Обработка данных осуществлялась при помощи пакета компьютерных программ «STATISTICA 6.0».

Результаты исследования. По экспресс-опроснику «Индекс толерантности» в обследуемых группа студентов преобладает средний уровень толерантности (индекс толерантности), т. е. для данных респондентов характерно сочетание как толерантных, так и интолерантных черт. В одних социальных ситуациях они ведут себя толерантно, в других могут проявлять интолерантность. Для студентов 2 курса характерны более низкие значения индекса толерантности в пределах его средних показателей, чем для студентов 3 и 4 курсов (рис. 1).

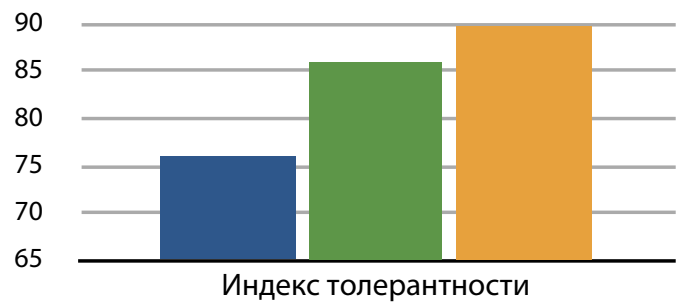

2 курс

3 курс

4 курс

Рис. 1. Статистически достоверные различия уровней толерантности у студентов 2-4 курсов по результатам экспресс-опросника «Индекс толерантности» (Г. У. Солдатова с соаврт.) $(\mathrm{p}<0,05)$

Методика диагностики общей коммуникативной толерантности В. В. Бойко, как уже говорилось выше, позволяет диагностировать толерантные и интолерантные установки личности, проявляющиеся в процессе общения. Пункты опросника сгруппированы в 9 шкал.

Шкалы:

-неприятие или непонимание индивидуальности другого человека (шкала I);

-использование себя в качестве эталона при оценке поведения и образа мыслей других людей (шкала II);

-категоричность или консерватизм в оценках других людей (шкала III);

-неумение скрывать или сглаживать неприятные чувства при столкновении с некоммуникабельными качествами партнеров (шкала IV); 
-стремление переделать, перевоспитать партнеров (шкала V);

-стремление подогнать партнера под себя, сделать его «удобным» (шкала VI);

-неумение прощать другим ошибки, неловкость, непреднамеренно причиненные вам неприятности (шкала VII);

-нетерпимость к физическому или психическому дискомфорту, создаваемому другими людьми (шкала VIII);

-неумение приспосабливаться к характеру, привычкам и желаниям других (шкала IX).

Показано, что для студентов 2 курса характерны высокие значения по шкалам I, II, III, IV,V и VII по сравнению со студентами 3 и 4 курсов (рис. 2).

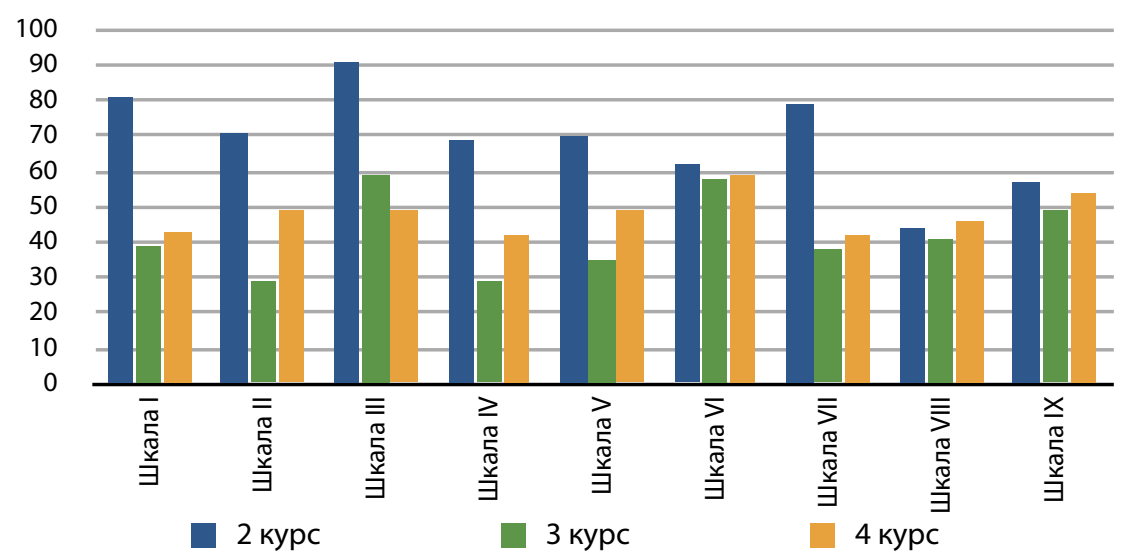

Рис. 2. Статистически достоверные различия между группами респондентов по методике диагностики общей коммуникативной толерантности

(В. В. Бойко) $(p<0,05)$

При сравнении показателей шкал студентов 3 и 4 курсов, у студентов 3 курса показатели выше по шкалам II, III, IV и IX (рис. 3).

Уменьшение различий по показателям шкал у студентов старших курсов может говорить о том, что в процессе совместной учебной деятельности и эффективной межнациональной и межкультурной политики вуза этническая толерантность повышается, стираются национальные стереотипы восприятия представителей различных этнических групп.

При анализе полученных данных по методике «Типы этнической идентичности» (Г. У. Солдатова, С. В. Рыжова) в группах респондентов можно также выделить распределение определенных типов. Авторы методики выделяют следующие типа этнической толерантности: этнонигилизм, этническая индифферентность, норма, этноэгоизм, этноизоляционизм и этнофанатизм. 


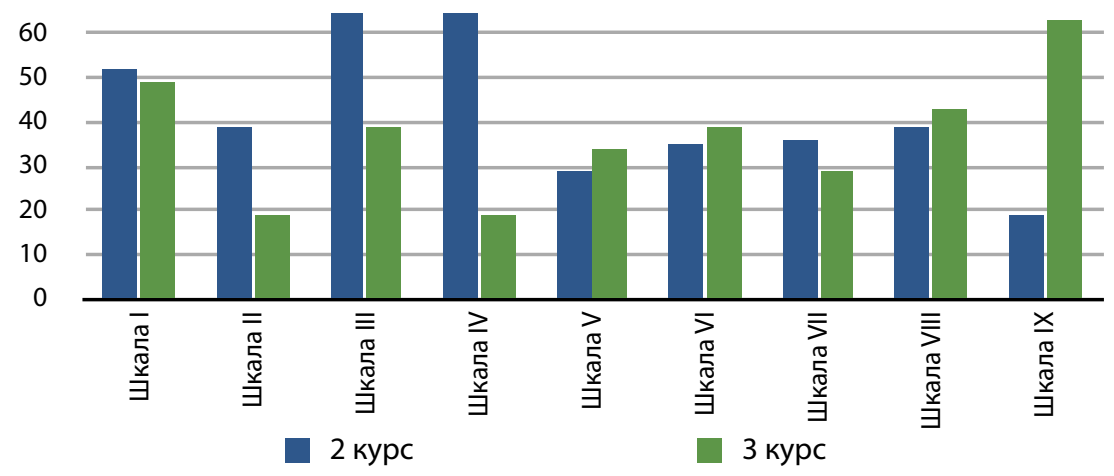

Рис. 3. Статистически достоверные различия между группами респондентов по методике диагностики общей коммуникативной толерантности

(В. В. Бойко) $(p<0,05)$

Для студентов 2 курса было характерно преобладание типа «этнонигилизм», т. е. для данной группы респондентов характерен отход от собственной этнической группы и поиск устойчивых социально-психологических ниш. Для третьекурсников преобладающим этническим типом стала этническая индифферентность, т. е. неопределенность этнической принадлежности, неактуальность этничности. Для 4 курса преобладающим типом стала норма, т. е. оптимальный баланс толерантности по отношению к собственной и другим этническим группам. Данный тип говорит о наличии у респондентов уже более устойчивых ценностей, идеалов, высокой внутренней культуре и гармоничной личности (рис. 4).

Проведенное исследование показало, что процесс обучения приводит к снижению деструктивных стереотипов относительно представителей тех или иных этнических групп, увеличению количества и качества межкультурных связей. Поэтому одной из основных задач образовательного процесса в современных вузах должна стать задача формирования толерантности и укрепление межнационального и межкультурного взаимодействия. Так, принятая Федеральная целевая программа «Формирование установок толерантного сознания и профилактика экстремизма в российском обществе» (2001-2005 гг.) предполагает разработку и внедрение в образовательные учреждения специальных программ, направленных на формирование толерантного сознания, веротерпимости и обучение межкультурному диалогу.

Однако на сегодняшний день в современных вузах политика межкультурного взаимодействия весьма слаба. Это приводит к тому, что многие национальные, религиозные и культурные феномены, являющиеся неотъемлемой частью жизни той или иной этнической группы, в обществе, где увеличивается уровень ксенофобии, воспринимаются молодежью как негативные. 
В связи с этим в современных вузах необходимо развитие системы институционального одобрения, стимулирования и поддержки толерантного поведения. Многими вузами в процесс профессиональной подготовки включаются дисциплины не только ориентированные на усвоение студентами профессиональных умений и навыков, но и на практическую подготовку к межкультурному взаимодействию $[7,13]$.

\section{Типы этнической идентичности}
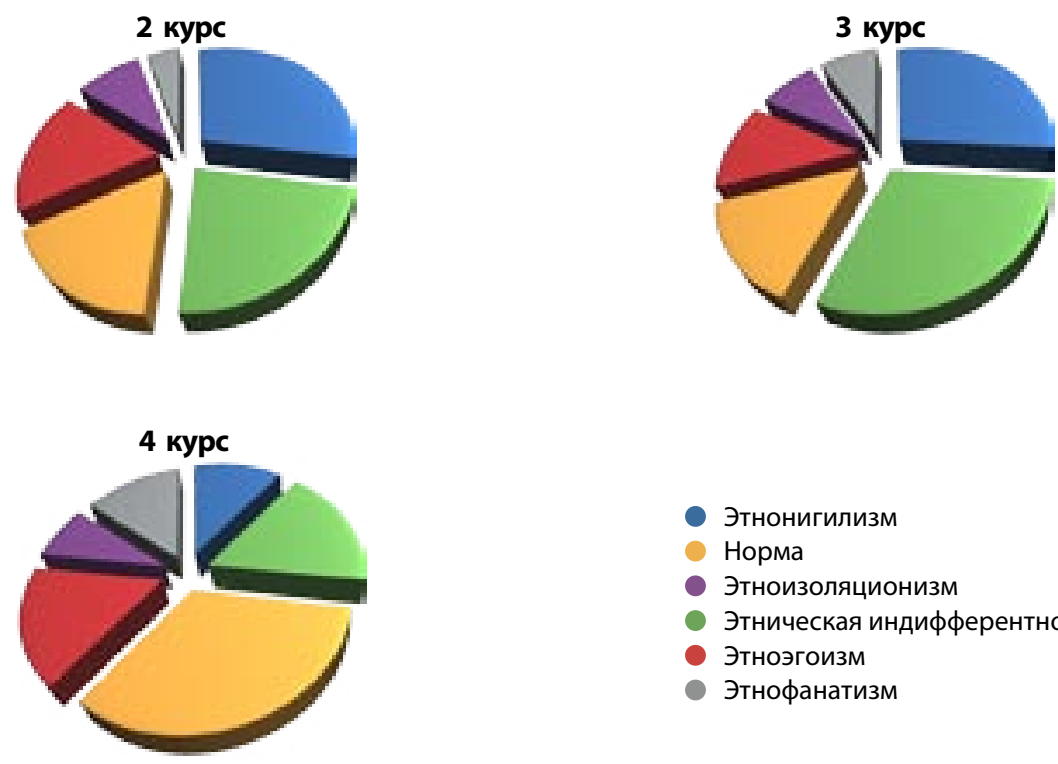

\author{
Этнонигилизм \\ Норма \\ Этноизоляционизм \\ Этническая индифферентность \\ Этноэгоизм \\ Этнофанатизм
}

Рис. 4. Статистически достоверные различия распределения типов этнической толерантности в группах респондентов по методике «Типы этнической идентичности» (Г. У. Солдатова, С. В. Рыжова) $(p<0,05)$

Многими исследователями говорится о необходимости в рамках процесса обучения формировать у студентов кросскультурную компетентность, развивать личностные качества, способствующие успешной социальной адаптации к профессии в современных кросскультурных условиях, эффективные способы взаимодействия в различных как профессиональных, так и кросскультурных ситуациях $[7,8,13]$.

Ведущими направлениями противодействия интолерантным проявлениям и экстремистской деятельности в вузе, по мнению О. А. Селивановой, должны стать:

-научно-методическое и аналитическое обеспечение профилактики экстремизма; 
-нормативно-правовое обеспечение системы профилактики экстремизма;

-организационно обеспечение функционирования системы профилактики экстремизма [6].

Данное исследование требует дальнейшего углубления в изучении проблематики. Ведь феномен этнической толерантности бесспорно является динамическим образованием, которое подвергается изменениям под действием как внешних, так и внутренних факторов. Ведь само по себе формирование толерантных установок в российском обществе - весьма сложная задача, которая связана с рядом экономических (уровень жизни людей, наличие социальной защиты и т. д.), политических (недопустимость межнациональной розни, веротерпимость и т. д.) и социально-культурных (духовный и нравственный кризис общества) трудностей.

\section{Литература}

1. Баев В. И. Формирование принципов толерантности - залог нравственного здоровья общества // Среднее профессиональное образование. - 2009. № 3. - C. 22-24.

2. Зорина Т. П. Формирование межэтнической толерантности студентов при изучении курса социальной психологии // Культура и искусство: традиции и современность. Материалы международной очно-заочной практической конференции. - Чебоксары, 2012. - С. 228-231.

3. Крысько Т. С. Толерантно ориентированное образование - условие самосовершенствования личности // Социальная психология: учебник для вузов. М.: Эксмо, 2010. - 688 с.

4. Лабунская В. А. Самооценка внешнего облика на различных этапах жизненного пути // Развитие психологии в системе комплексного человекознания. М.: Изд-во «Институт психологии РАН», 2012. - Ч 1. - С. 331-338.

5. Общественное мнение - 2011. - М.: Левада-Центр, 2012. - С. 181-183.

6. Селиванова О. А. Проблемы профилактики интолерантных взаимоотношений в условиях высшего учебного заведения // Вестник Тюменского государственного университета. - 2012. - № 1. - С. 216-221.

7. Тарасова С. М., Науменко А. В. Моделирование образовательного процесса вуза как фактора социальной адаптации студента в современных кросскультурных условиях // Вектор науки ТГУ. - 2012. - № 1(8). - С. 281-284.

8. Christina T. Williams, Laura R. Johnson Why can't we be friends?: Multicultural attitudes and friendships with international students Original Research Article // International Journal of Intercultural Relations, Vol. 35, Is. 1, January 2011, P. 41-48.

9. Dunne $C$. Exploring motivations for intercultural contact among host country university students: An Irish case study Original Research Article // International Journal of Intercultural Relations, Vol. 37, Is. 5, September 2013, P. 567-578.

10. Corneo G., Jeanne O. A theory of tolerance Original Research Article // Journal of Public Economics, Vol. 93, Is. 5-6, June 2009, P. 691-702. 
11. Racheal A. Ruble, Yan Bing Zhang Stereotypes of Chinese international students held by Americans Original Research Article // International Journal of Intercultural Relations, Vol. 37, Is. 2, March 2013, P. 202-211.

12. Zainal K., Taip Abu D., Mohamad Z. The effect of ethnic relations course on the students perceptions towards ethnic relations among first year students of one public university in Malaysia Original Research Article // Procedia - Social and Behavioral Sciences, Vol. 2, Is. 2, 2010, P. 3596-3599.

13. Thijs J., Verkuyten M. Ethnic attitudes of minority students and their contact with majority group teachers Original Research Article // Journal of Applied Developmental Psychology, Vol. 33, Is. 5, September-October 2012, P. 260-268.

14. Verkuyten $M$. Assimilation ideology and situational well-being among ethnic minority members Original Research Article // Journal of Experimental Social Psychology, Vol. 46, Is. 2, March 2010, P. 269-275. 